\title{
Technical and economic evaluation of maceration of red grapes for production everyday wine
}

\author{
F. Pezzi, ${ }^{1}$ C. Caprara, ${ }^{2}$ D. Friso, ${ }^{3}$ B. Ranieri ${ }^{4}$ \\ ${ }^{1}$ Department of Agricultural and Food Sciences, University of Bologna, Italy; ${ }^{2}$ Department of \\ Agricultural Sciences, University of Bologna, Italy; ${ }^{3}$ Department of Land, Environment, Agriculture \\ and Forestry - TeS.A.F., University of Padova, Italy; ${ }^{4}$ Winery of Forli and Predappio, Italy
}

\begin{abstract}
For red wines, the phase of maceration is fundamental as it affects important features such as colour, aroma and flavour. For wines for everyday consumption these features must provide an easily drinkable product with a good quality basis that is consistent over time. In recent years two methods of maceration seem to guarantee these objectives better than others, while also allowing good work organization and automation: hot maceration and pneumo-carbonic pumping over. These techniques have been evaluated in a large winery, defining their production potential, labour requirements, energy consumptions and economic costs. Chemical and sensory evaluations were carried out on wines produced from grapes with the same characteristics.
\end{abstract}

\section{Introduction}

Although consumer attention is increasingly directed towards top of the range wines, most of the wine drunk in this country and in other parts of the world is table wine for everyday use in the home.

These everyday wines, while falling into a limited price range, must be easily drinkable and with a good basic quality that remains constant over time.

The most important quality aspects for red wines regard the colour, flavour and aromas. A vinification phase that can have a significant influence on these characteristics is the maceration (Arfelli et al. 2001; Lambri and Silva 2004).

Correspondence: Fabio Pezzi, Department of Agricultural and Food Sciences, University of Bologna, Via G. Fanin 50, 40127 Bologna, Italy.

Tel. + 39.051.2096187.

E-mail: fabio.pezzi@unibo.it

Key words: grape maceration, energy consumptions, economic costs

Contributions: the authors contributed equally.

Conflict of interests: the authors declare no potential conflict of interests.

(C) Copyright F. Pezzi et al., 2013

Licensee PAGEPress, Italy

Journal of Agricultural Engineering 2013; XLIV(s2):e64

doi:10.4081/jae.2013.s2.e64

This article is distributed under the terms of the Creative Commons Attribution Noncommercial License (by-nc 3.0) which permits any noncommercial use, distribution, and reproduction in any medium, provided the orig-
In the last years two methods of maceration appear to guarantee the quality aspects of wines better than the others, while also allowing a good organization and automation of the work: hot maceration and pneumo-carbonic pumping over (Amati, 1985; Celotti and Rebecca 1998; Celotti and Franceschi 2004)

The objective of this research was to evaluate these two techniques in a large winery, analysing the production potential, labour requirements, energy consumption and economic costs.

Chemical and sensorial evaluations were also conducted of the wines obtained, which were produced from grapes with the same characteristics.

\section{Materials and methods}

The vinification trials were conducted at the Forlì-Predappio Winery (FC) during the 2012 grape harvest.

The plant productivity and energy consumptions were evaluated during the entire wine-making process of 2012 , while the product quality was evaluated on volumes of around $1000 \mathrm{hl}$ of wine obtained from Sangiovese grapes with homogeneous sanitary and chemical characteristics.

The plants were:

- Hot macerator constituted by the BioThermo/Cooler System of Della Toffola S.p.A (BioThermo/Cooler System Guide).

- Pneumo-carbonic fermentation tanks based on the Ganimede Method of Ganimede S.r.l. (Metodo Ganimede Guide).

\section{Della Toffola hot macerator}

The hot maceration plant used in the winery forms a continuous process as shown in Figure 1.

After the crushing/stemming, the crushed grapes are treated with sulphur dioxide and then accumulated in a stopover tank (A) for an estimated time of approximately $60 \mathrm{~min}$. In this tank the crushed grapes undergo enzymatic activity and continuous agitation for the homogenization of the mass.

The crushed grapes are then continuously withdrawn by a Monho pump to pass through the tube heat exchanger (B), which is fed with hot water at $93^{\circ} \mathrm{C}$ produced by the boiler (E), through which the product passes 18 times within 2 minutes.

The crushed grapes enter the exchanger at a temperature of about 25$27^{\circ} \mathrm{C}$ and exit at $80.5^{\circ} \mathrm{C}$. The sharp rise in temperature is obtained not only with the contribution of the hot water but also by the reuse of a part of the hot must drained by the drum separator (C). This fraction of must is further heated inside the exchanger and is united to the crushed grapes on entry to increase the temperature and make the mass more fluid.

From the separator, the must not reused for the pre-heating of the crushed grapes is reunited with the pomace in a tank (D) equipped 
with an agitator and placed under vacuum ( -0.928 bar $)$ by a liquid ring vacuum pump.

In this phase the product is flash cooled by the joint action of the vacuum and a heat exchanger (L) that acts as a steam condenser for the reintegration of the condensate.

The product exits the vat at a temperature of $45^{\circ} \mathrm{C}$ and is sent to a continuous drip-press (I) for the definitive separation of the pomace.

The extracted must is filtered by a rotating filter $(\mathrm{H})$, cooled in the exchanger (G) and collected in the tank (F) where it is inoculated with selected yeasts, cooled for 4-5 days and maintained at a temperature of $20^{\circ} \mathrm{C}$ by indirect cooling with glycol.

The end product then undergoes a tangential filtration.

\section{Ganimede fermentation tanks}

Wine-making with the Ganimede plant is a discontinuous process that in the Forlì-Predappio winery is done with 7 tanks, four of which are of $74 \mathrm{~m}^{3}$ and three of $184 \mathrm{~m}^{3}$. As the tanks are used approximately $80 \%$ full, the useful capacity results as being $678 \mathrm{~m}^{3}$ of crushed grapes that, considering a density of crushed grapes $=1090 \mathrm{~kg} \mathrm{~m}^{-3}$, corresponds to a mass of $739 \mathrm{t}$.

The Ganimede process (Figure 2), after filling the vat with the crushed grapes, is based on the exploitation of the $\mathrm{CO}_{2}$ freed by the fermentation. This is collected below the funnel-shaped diaphragm and as it leaks, gradually remixes the cap of pomace that has formed in the upper part of the mass (stage 1). At regular intervals, the opening of the by-pass rapidly releases the $\mathrm{CO}_{2}$ upwards and causes the fall and complete immersion of the cap of pomace in the liquid mass (stage 2). The closing of the by-pass restarts the cycle with the stratification of the pomace in the upper part and the accumulation of $\mathrm{CO}_{2}$ below the headspace (stage 4). During this sequence, the mass may be drained (délestage) with the complete extraction of the must, followed a few hours later by its reintroduction on the cap of pomace to accentuate the action of leaching and extraction (stage 3). In the controlled plant the délestage was realized twice per cycle.

At the end of maceration the product is extracted with a belt conveyor and sent by a series of screw conveyors to a dripper that partially separates the must then consigns the pomace to a membrane crusherstemmer for a complete extraction.

This maceration process is also completed by a tangential filtration.

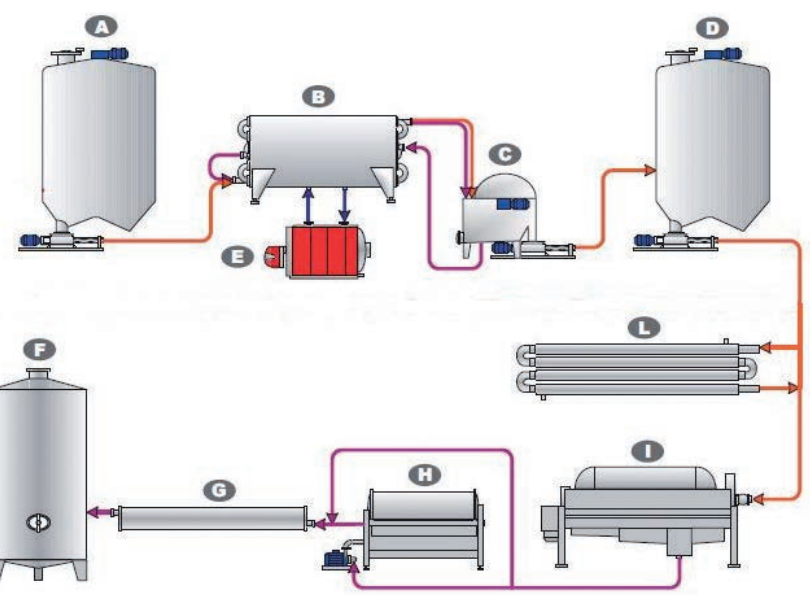

Figure 1. Flow chart of the thermal maceration plant. A: stopover tank; B: tube heat exchanger; C: drum separator; D: storage tank; E: boiler; F: fermentation tank; G: thermal exchanger; $\mathrm{H}$ : rotating filter; I: continuous drip-press; L: vacuum and heat exchanger.

\section{Evaluation of the processes}

The electricity and thermal consumption have been evaluated for both processes, considering the individual elements and their use for the execution of the operating cycles. The comparison of the two maceration techniques was only made between the characteristic elements of each plant, excluding the phases in common: crushing and stemming, plant loading, final tangential filtration and storage in tank.

An economic evaluation was done on the basis of the measured energy consumption and the parameters reported in Table 1 to obtain a unit cost of the process based on the productivity observed in the winery (ASAE Standards 2011).

The same elements were also used to extend the evaluation by hypothesizing different production levels.

A chemical analysis and sensorial analysis by means of the recognition test (triangle test, preference test and descriptors test) were conducted on the wines obtained.

\section{Results}

During the 2012 grape harvest, the Della Toffola hot maceration plant in the Forlì-Predappio winery was utilized for 22 days with a daily use of $20 \mathrm{~h}$, and an hourly productivity of around $15 \mathrm{t} \mathrm{h}^{-1}$.
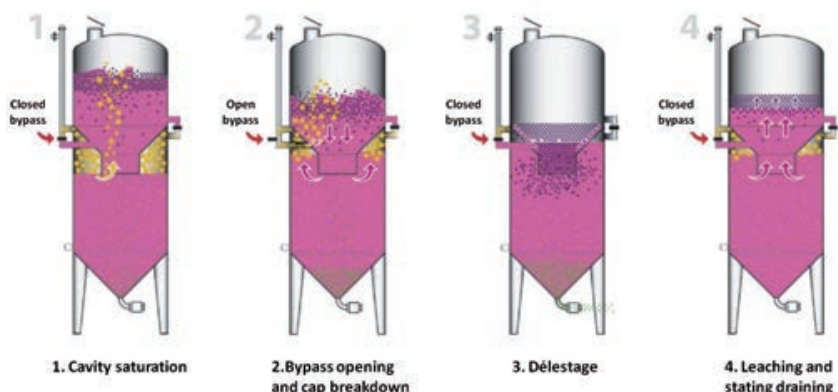

3. Délestage

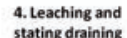

Figure 2. Stages of the maceration process in the Ganimede fermentation tank.

Table 1. Elements used for the economic evaluation.

\begin{tabular}{lcc}
\hline Economic parameters & Hot maceration & Ganimede system \\
Market price - MP $(€)$ & 320000 & 825000 \\
Residual value (\%MP) & 5 & 10 \\
\hline Max. economic life (years) & 15 & 20 \\
Plant use life (h) & 5000 & 8000 \\
\hline Daily use (h day-1) & 20 & 24 \\
Interest rate (\%) & 5 & 5 \\
\hline Labor hours/hours of plant use & 1.50 & 0.57 \\
Annual maintenance: & 70 & 50 \\
- labor (h) & 5000 & 2500 \\
- spare parts $(€)$ & & \\
\hline
\end{tabular}

Wage $\left(€ \mathrm{~h}^{-1}\right) 1616$

Energy cost:

$\begin{array}{lll}\text { - electricity }\left(€ \mathrm{kWh}^{-1}\right) & 0.08 & 0.08\end{array}$

- methane (€ m-3)
0.40 
The Ganimede plant was instead used for 4 production cycles, each one lasting 6 days for a total of 24 days. Considering the overall capacity of the plant, the daily productivity is around $141 \mathrm{t}$.

\section{Energy consumption}

Figure 3 reports the electricity consumption on an hourly basis for the different phases of the Della Toffola hot maceration process, obtained from the sum of the individual elements utilized in the plant. The total electricity consumption amounts to $169.8 \mathrm{kWh}$, with a higher incidence in the phases of vacuum cooling (D-L), pressing (I) and filtering $(\mathrm{H})$ that follow the central phase of hot maceration.

For the thermal consumptions linked to the hot maceration, with a flow of crushed grapes of $15 \mathrm{t} / \mathrm{h}$, the parameters characterizing the process are:

$\mathrm{m}_{\text {crushed }}=15 \mathrm{t}$

$\mathrm{c}_{\text {crushed }}=0.86 \mathrm{kcal} / \mathrm{kg}^{\circ} \mathrm{C}$

$\mathrm{T}_{\text {in_crushed }}=27^{\circ} \mathrm{C}$

$\mathrm{T}_{\text {out_crushed }}=80.5^{\circ} \mathrm{C}$

The amount of heat necessary to warm the crushed grapes in stationary conditions is:

$$
\begin{gathered}
\Delta Q_{\text {crushed }}=m_{\text {crushed }} \cdot c_{\text {crushed }} \cdot\left(T_{\text {out_crushed }}-T_{\text {in_crushed }}\right) \\
\cong 690150 \mathrm{kcal}
\end{gathered}
$$

Corresponding to $46010 \mathrm{kcal} \mathrm{t}^{-1}$ that, with a calorific power of methane of $8200 \mathrm{kcal} \mathrm{m}^{-3}$, is equivalent to a theoretical methane consumption of $5.61 \mathrm{~m}^{3}$.

When the crushed grape is heated reusing a part of the hot must, as happens in the process, part of the heat is supplied by the must. However, this in turn cools down, so the thermal energy provided by the water from the boiler must finish the heating of the crushed grape (up to $80.5^{\circ} \mathrm{C}$ ) and return the cooled must to the same temperature.

From the point of view of energy requirements, the situation does not change substantially from that with only water heating. The benefits of reintroducing part of the hot must are mainly linked to a better homogenization of the system, improved product flow and a reduction in thermal shock.

Figure 4 reports the electricity consumption for the different phases of the Ganimede process for the entire 6-day maceration cycle. Total electricity consumption amounts to $1759.6 \mathrm{kWh}$, with the highest incidence (43\%) for the transport phase that, in this case, is penalized by a considerable distance of the tanks from the draining-pressing area.

Given that every maceration cycle lasts $144 \mathrm{~h}$, an average hourly energy consumption of $12.22 \mathrm{kWh}$ can be estimated.

\section{Economic evaluations}

For the Della Toffola plant the calculation of the operating cost, based on the 2012 figures and the economic parameters in Table 1, provides an annual quota of fixed costs of $42634 €$, which is equal to $96.9 € \mathrm{~h}^{-}$ 1. The hourly incidence of the variable costs corresponds to $71.2 € \mathrm{~h}^{-1}$, of which $24 € \mathrm{~h}^{-1}$ is for labour, $13.6 € \mathrm{~h}^{-1}$ for electricity and $33.7 € \mathrm{~h}^{-}$ ${ }^{1}$ for thermal energy. The total hourly cost is therefore $168.1 € \mathrm{~h}^{-1}$, which corresponds to a unit cost of $11.2 € \mathrm{t}^{-1}$ of processed product.

For the Ganimede plant the fixed costs are affected by the high purchasing cost of the plant and correspond to $82854 €$ year $^{-1}$, with an average hourly incidence of $143.8 € \mathrm{~h}^{-1}$, while the share of variable costs is $10.1 € \mathrm{~h}^{-1}$, of which $9.1 €$ is for labour and $1 €$ for electricity. The total hourly cost is $153.9 € \mathrm{~h}^{-1}$, corresponding to a unit cost of 30 $€ \mathrm{t}^{-1}$, about three times that of the Della Toffola plant.

In theory the trend of the costs of the two plants can be simulated taking into account a variability in annual production. The result (Figure 5) shows a fairly flat curve for the hot maceration plant, affected by the high incidence of variable costs. On the contrary the Ganimede plant, because of the greater weight of the fixed costs, shows a clearly decreasing trend. Despite this, considering also a particular situation of underutilization of the Della Toffola plant and greater utilization of the Ganimede plant, the difference between the unit costs reduces but still remains evident.

\section{Chemical and sensorial analyses}

Despite coming from grapes with homogeneous characteristics, the chemical analyses have demonstrated different values for the two wines. More specifically, the values in the wine obtained with hot maceration are lower: total acidity 4.91 vs. $6.05 \mathrm{~g} \mathrm{l}^{-1}$; volatile acidity $0.17 \mathrm{vs.}$ $0.23 \mathrm{~g} \mathrm{l}^{-1}$; total $\mathrm{SO}_{2} 56$ vs. $72 \mathrm{~m} \mathrm{gl}^{-1}$; total polyphenols 1572 vs. 2043 ; colour intensity 7.19 vs. 8.73 . The low levels of the first 3 parameters are positive for the characteristics of the wine, while the last two may be signs of weakness.

The sensorial analysis, conducted with a panel of 27 expert winetasters, displayed a significant difference $(\mathrm{p}=0.001)$ between the two

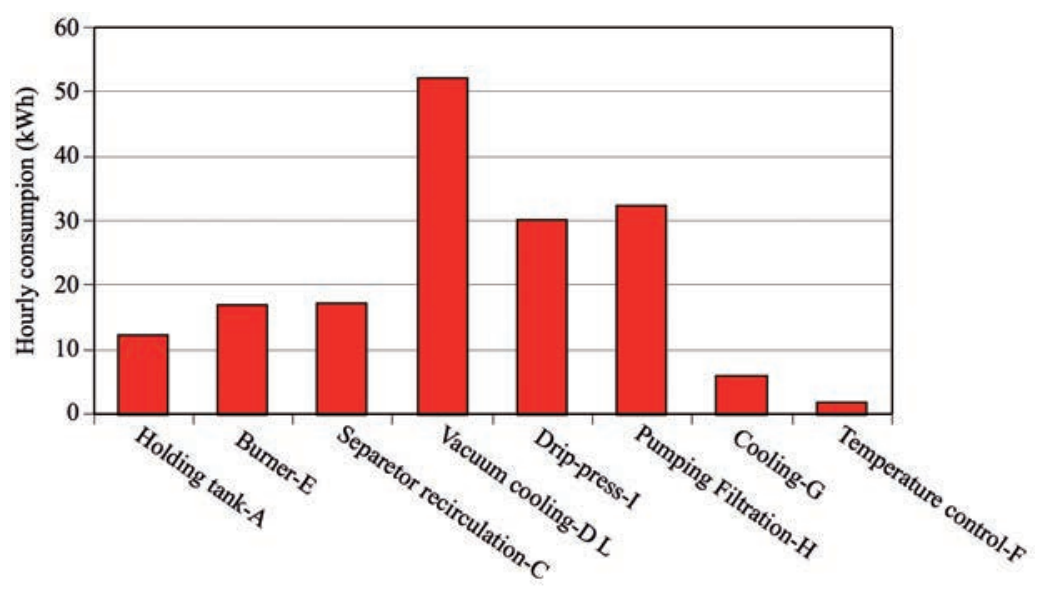

Figure 4. Electricity consumption for an operating cycle of the Ganimede plant.

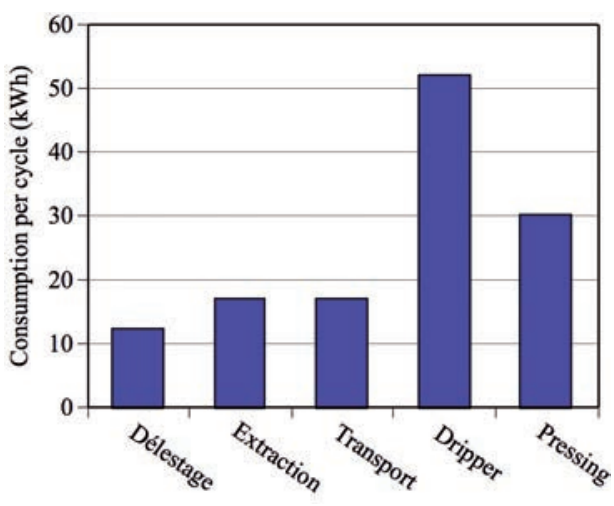

Figure 5. Unit costs according to annual productivity. 
wines. The preference of 15 out of the 27 , even if not significant, was for the hot macerated product. The descriptive evaluation (Figure 6) identified two wines with completely different sensorial characteristics. The wine obtained from the hot maceration was distinguished by greater aroma and freshness, resulting as suitable to be drunk young. The wine obtained with the Ganimede system instead showed a more complex and evolved structure, destined to improve over time.

The chemical and organoleptic differences of the two wines obtained determine a different market destination: the hot macerated product is mainly suitable for integration with other wines to enhance the levels of freshness and aromas; the wine produced with the Ganimede system is instead destined to the production of more traditional wines that maintain the characteristics of the grape variety.

The commercial value of the two wines, destined mainly for everyday consumption, is quite similar, even if the increased demand for hot macerated wine in recent years has allowed selling prices to rise by around $10 \%$.

\section{Conclusions}

The analysis of the maceration processes has demonstrated clear differences in the productivity, energy consumption and unit costs of production of the two plants.

The hot maceration uses more energy, but, thanks to the speed of the process that guarantees high productivity, the unit cost is lower. Furthermore, due to the high incidence of the variable costs, it appears less important that the production potential of this plant is fully exploited.

On the contrary the Ganimede plant has a higher unit cost that, due to the high purchase price, requires maximum exploitation of its annual production potential.

The chemical and sensorial evaluations describe two extremely diverse wines that, although being in the same commercial price range, can have two different and complementary destinations: the aroma and freshness of the hot macerated product makes it more suitable for integrating and improving other wines, while the other appears to be destined to the production of more traditional wines.

This quality difference fully justifies the choice of the Forlì-Predappio winery, which, although involving different production costs, has recently introduced both maceration systems to widen its range of red wines and respond more efficiently to the varied demands of the market.

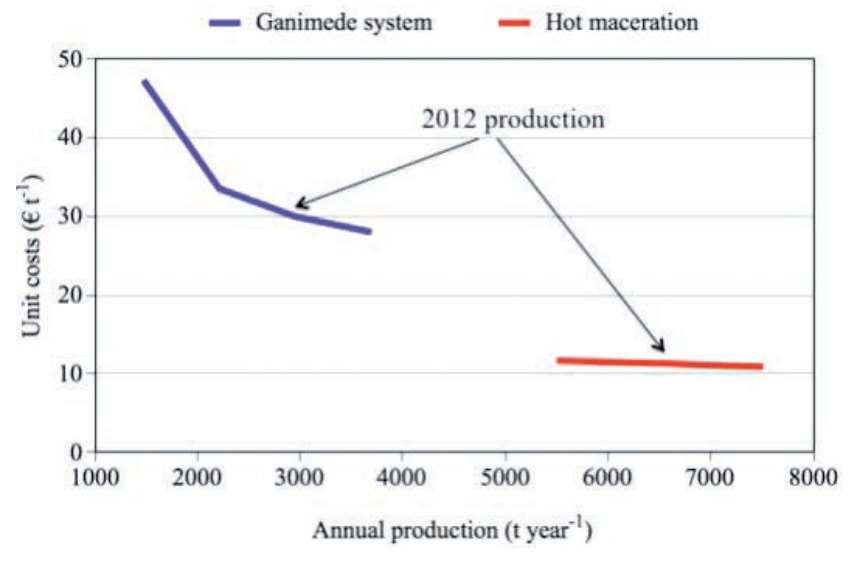

Figure 6. Descriptive evaluation of the two wines obtained.

\section{References}

Amati, A. 1985. Le possibili utilizzazioni della termomacerazione in enologia. Atti dell'Accadademia Italiana della Vite e del Vino. 37:143-155.

ASAE Standards 2011. EP497.7. Agricultural Machinery Management. St. Joseph, Mich., USA.

Arfelli, G., Sartini, E. and Gennari, L. 2001. La vinificazione in rosso. Il divulgatore. 24 (4/5): 34-37.

BioThermo/Cooler System Guide. 2013. Available from: http://www.dellatoffola.it Accessed: May 2013.

Celotti, E. and Rebecca S. 1998. Expériences récentes de thermomacération des raisins rouges. Revue des Enologues. 89:14-18.

Celotti, E. and Franceschi, D. 2004. Gestion de certaines variables dans la macération des raisins rouges. Revue des Enologues. 110:24-27.

Lambri, M. and Silva, A. 2004. Tecniche di macerazione e caratteri qualitativi dei vini rossi. L'informatore Agrario. 13:77-81

Metodo Ganimede Guide. 2013. Available from: http://www. ganimede.com Accessed: May 2013. 